\title{
THE BEHAVIOR OF DIPLOECITON NEVERMANNI, A STAPHYLINID BEETLE ASSOCIATED WITH ARMY ANTS ${ }^{1}$
}

\author{
By Roger D. Akre and Richard L. Torgerson ${ }^{2}$ \\ INTRODUCTION
}

The genus Diploeciton of staphylinid beetles contains two known species, $D$. constrictum Wasmann and D. nevermanni Reichensperger, both collected only with the army ant Neivamyrmex pilosus (F. Smith). D. constrictum has been collected once in an emigration column at Minas Geraes, Brazil, by J. F. Zikan and D. nevermanni has been collected twice in Costa Rica: by F. Nevermann from an emigration column at Hamburgfarm and in a nest by H. J. C. Schmidt at Farm La Caja (Reichensperger, 1939). The literature contains taxonomic descriptions and mention of the host ant, but no other information is available.

Diploeciton are unusual myrmecoid staphylinids belonging to the Aleocharinae: Dorylomimini. They are shiny reddish-brown to dark brown in color while their host, $N$. pilosus, is shiny black; otherwise the beetles resemble their host. They have "pseudogasters" formed by the enlargement of the 6th-8th abdominal segments which mimic the gasters of the army ants, a three segmented petiole (army ants have two segments), and a filiform process of unknown function on the venter of the petiole (Seevers, 1965). The beetles have functional wings and presumably can fly. The legs of the beetles are clothed with scattered hairs along their entire lengths, with the hairs becoming longer and denser on the inner surface of the distal end of the tibiae of the first and second pair of legs. The staphylinids do not have tufts of hairs for rubbing their host as do some of the ecitophilous histerids (Akre, I968).

A previous paper concerned with the behavior of ecitophilous staphylinids (Akre and Rettenmeyer, I966) covered methods used in studying army ants and their guests; additional methods are given by Rettenmeye:- (1963).

The findings reported here were conducted at the Smithsonian Tropical Research Institute (Barro Colorado Island) in the Canal

\footnotetext{
${ }^{1}$ Scientific Paper Number 3131. Study supported in part by Grant GB5220 from the National Science Foundation. Work was conducted under Project 1802, insect behavior.

${ }^{2}$ Assistant Professor and Research Assistant, Washington State University, Department of Entomology.
} 
Zone during 1967. Our collections of $D$. nevermanni in the Canal Zone have extended the distribution of this beetle several hundred miles. This would imply a continuous distribution of the genus Diploeciton from Costa Rica to Brazil.

\section{ETHOLOGY}

On I I February 1967 we found a raid column of $N$. pilosus crossing a damp stream bed at 3:00 PM. Upon our return at $7: 03$ PM these same ants were engaged in an emigration. Brood was seen being carried, the column was 2-4 ants wide and $90 \%$ of the traffic was moving in one direction. Myrmecophiles were continuously abundant in the column and between 7:03-II:45 PM, when the observations were terminated, a male and a female $D$. nevermanni were taken from the column. The queen passed our stationary observation post at 9:24 PM but guests were collected until ro minutes before observations ended. The specimens of Diploeciton were taken running in the center of the column and were difficult to distinguish from the ants except for their color and long hind legs. The myrmecoid abdomen was held at approximately $45^{\circ}$ from the perpendicular while the beetles were running.

A large sample of ants, still carrying brood, was taken with bottle aspirators at II:45 PM. This sample was later found to contain 4 additional males and I female of Diploeciton.

On I2 February all Diploeciton were placed in laboratory nests with about $2000 N$. pilosus workers and were observed for a minimum of one hour each day until I March when the contents of the nests were preserved.

The staphylinids spent nearly all their time in the laboratory nests grooming worker ants their size or smaller. They were never seen grooming any of the major workers present. Grooming consisted of licking the head and thorax of the workers. Although the staphylinids groomed workers from a number of positions, Diploeciton had their own unique grooming position that was assumed most frequently (Fig. I). In this behavior the staphylinids are remarkably similar to the staphylinids Probeyeria pulex (Sanderson) and to a lesser extent Ecitophya bicolor Reichensperger (Akre and Rettenmeyer, 1966). While Probeyeria and Ecitophya straddled their host across the longitudinal axis of the body, Diploeciton assume a position parallel to, but slightly to one side and on top of, the ant. To position itself, a beetle grasps with its mandibles the scape of an antenna of an ant close to its base. It then positions its body parallel to the body of the ant and uses the first and third legs on the lower 


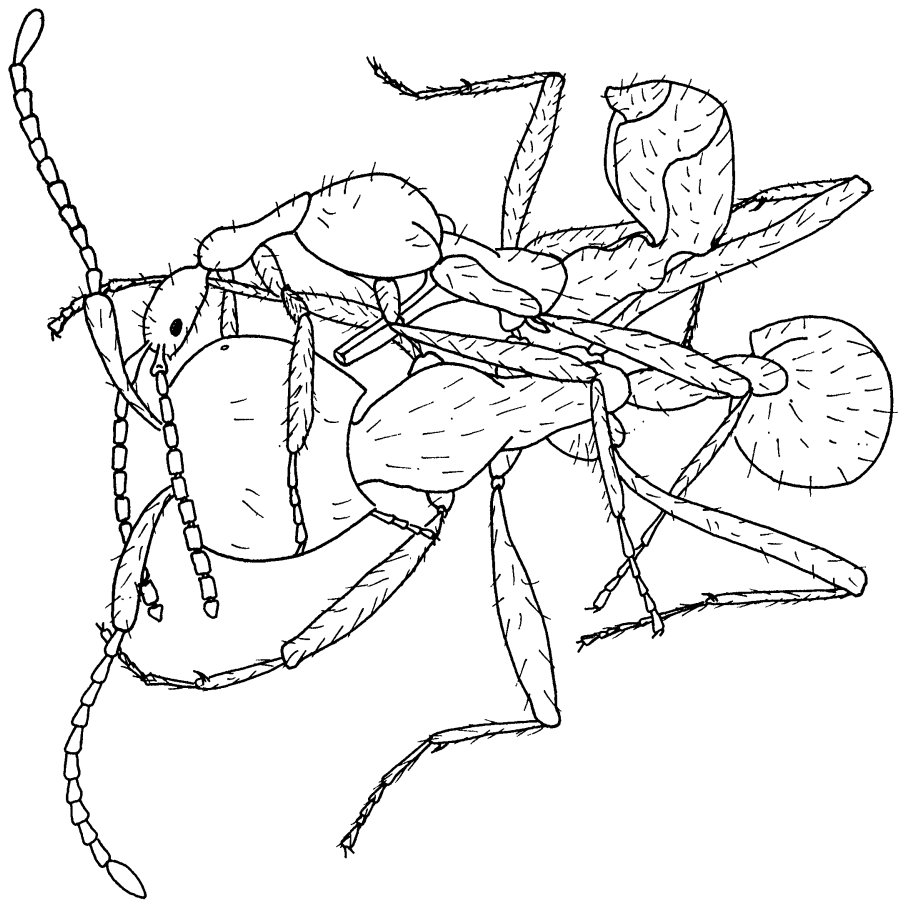

Figure 1. Diploeciton nevermanni in its unique grooming position on a worker of its host, $N$. pilosus. Drawing from a photograph.

side of the body to brace against the substrate. The three legs on the other side of the body then straddle the ant. The mesothoracic leg on the bottom curls under and around the thorax of the ant. This places the sternum of the beetle's thorax against the side of the thorax of the ant as though riding "sidesaddle". In this position the beetle rubs the ant with its legs. The mesothoracic lower leg rubs the bottom of the thorax and the upper legs rub on the dorsal area of the ant; the prothoracic leg usually rubs the head of the ant, the mesothoracic leg rubs on the thorax and gaster, while the metathoracic leg is used sparingly to rub the gaster of the ant. The rubbing strokes are rather slow and alternate between stroking the body of the ant and the staphylinid's own body. The front leg is rubbed on the head and thorax, both middle legs are rubbed on the elytra and the globular portion of the myrmecoid abdomen, while the metathoracic leg was rubbed only rarely on the abdomen. This intimate rubbing has been suggested as a means of acquiring colony 
odor (Rettenmeyer, 196I) and surely must serve some similar useful function because it is practiced by several different species of staphylinids (all Dorylomimini) and at least three species of histerids. The rubbing by Diploeciton calmed the ants being groomed and several ants groomed in this manner even seemed partially paralyzed. This condition of paralysis has been reported previously for ants rubbed by histerids (Akre, I968). Although the beetles were observed for long periods of time, no function was found for the filiform process on the petiole.

The staphylinid spent an average of 46 seconds grooming each ant (20 timed observations) and moved constantly from one ant to another. During infrequent periods of inactivity, the beetle was usuaily buried near the bottom of a large cluster of ants that was always present over the brood. The entire cluster remained stationary for periods up to several hours during these rare moments.

The staphylinids also groomed at intervals by running their antennae and front legs through their mouth parts. Although the globular portion of the abdomen was held $45^{\circ}$ from the perpendicular when the staphylinids ran, the abdomen was held perpendicular or tilted slightly forward when grooming ants (Fig. I). The 3-segmented petiole gives the abdomen considerable maneuverability and it can be thrust forward a considerable distance. The beetle rubbed the tip of the abdomen on the elytra quite frequently, a practice which also seems widespread among the ecitophilous staphylinids (Akre and Rettenmeyer, 1966).

Like other guests of army ants, Diploeciton fed on the brood of dolichoderine ants given to the $N$. pilosus as food as well as on army ant brood. However, the staphylinids were observed eating $N$. pilosus brood only three times, and may eat it only when booty is not available. They were extremely efficient in cutting open brood and, as reported previously (Akre and Rettenmeyer, 1966), the beetles were usually driven away by worker ants trying to get at the oozine juices.

The captured beetles behaved nonspecifically towards one another, in that the beetles antennated vigorously upon meeting but they always continued on their way. They were never seen grooming one another or in any intimate contact.

\section{SUMMARY}

The behavior of Diploeciton nevermanni is similar to that reported for several other ecitophilous staphylinids in that the beetles assume a unique position in grooming their host, Neivamyrmex pilosus. 
Grooming of ants is probably a means of acquiring colony odor. Diploeciton are predaceous on army ant brood.

AKRE, R. D.

\section{Literature Cited}

1968. The behavior of Euxenister and Pulvinister, histerid beetles associated with army ants. (Coleoptera: Histeridae; Hymenoptera: Formicidae: Dorylinae). Pan. Pac. Ent. 44: 87-101.

Akre, R. D. And C. W. Rettenmeyer

1966. Behavior of Staphylinidae associated with army ants (Formicidae: Ecitonini). J. Kansas Ent. Soc. 39: 745-782.

REICHENSPERGER, A. VON

1939. Beitrage zur Kenntis der Myrmecophilen- und Termitophilenfauna Brasiliens und Costa Ricas. VI. (Col. Hist. Staph.) Rev. de Ent. 10 (1) : 97-137.

RetTenmeyer, C. W.

1961. Arthropods associated with Neotropical army ants with a review of the behavior of these ants. (Arthropoda: Formicidae: Dorylinae). Ph.D. Dissertation, Univ. of Kansas, 605 pp., 77 Figs.

1963. Behavioral studies of army ants. Univ. Kansas Sci. Bull. 44: 281-465.

SEEVERS, C. H.

1965. The systematics, evolution and zoogeography of staphylinid beetles associated with army ants (Coleoptera: Staphylinidae). Fieldiana: Zool., $47(2):$ 139-351. 

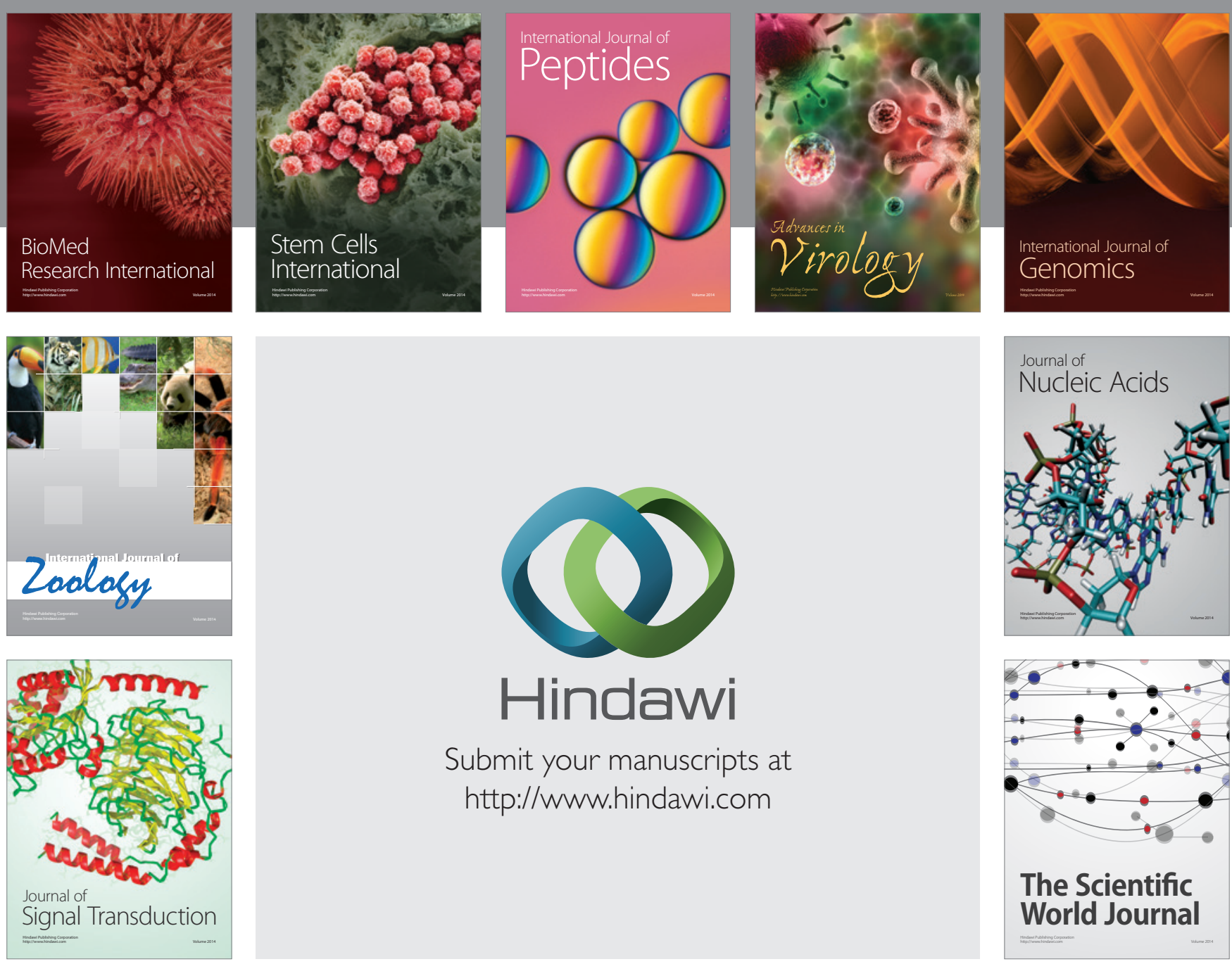

Submit your manuscripts at

http://www.hindawi.com
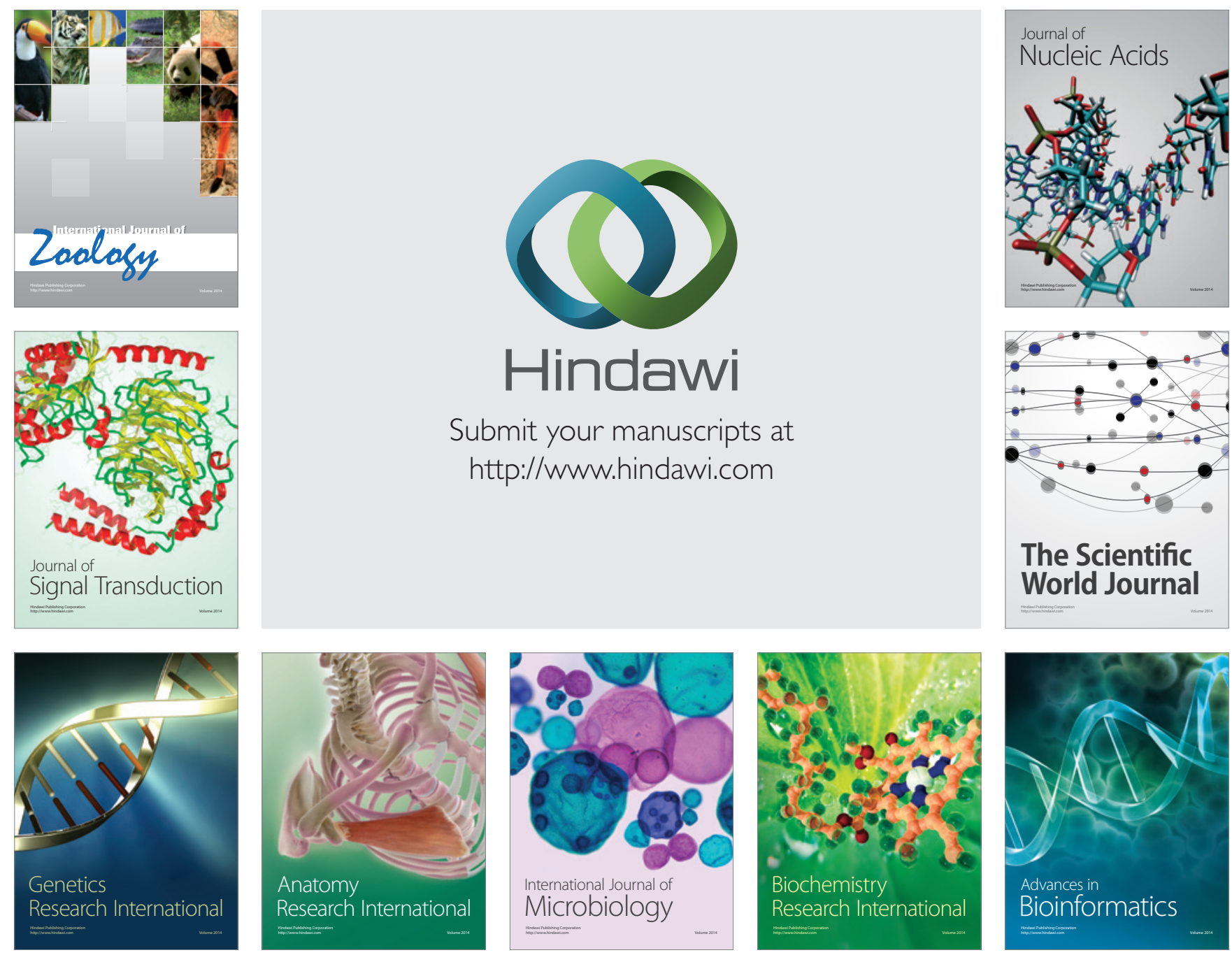

The Scientific World Journal
